\title{
Special issue introduction: geographical perspectives on food and nutrition insecurity in the global South
}

In 2015, the three editors of this special issue met at the annual conference of the Leverhulme Centre for Integrative Research on Agriculture and Health (LCIRAH) at the London School of Hygiene and Tropical Medicine. The LCIRAH event was an interdisciplinary conference that brought together leading researchers in the field of food and nutrition security. Most participants had backgrounds in agriculture, economics, nutrition science, and public health. We were three geographers working in our own ways on food and nutrition security in the global South. Although we had links and collaborations with various researchers from other disciplines represented at the conference, we carried geographers' worldviews into these forums. But then, over a coffee late in the conference, we pondered what exactly did that mean? What precisely do such perspectives 'bring to the table' in interdisciplinary contexts such as that at the LCIRAH conference?

This special issue can be considered one response to that question. The papers that constitute it do not come from participants from that LCIRAH conference, aside from the contribution by Pritchard et al. Rather they derive from a subsequent call for papers that was prompted by our conference experiences. Our call for papers sought to cast a net over the field. We asked for contributions from geographers working on food and nutrition security research and open-mindedly waited to see what would be hauled in. The papers in this special issue exhibit diverse praxis, but all share distinctive geographical traits. We do not claim that the collection provides a defining statement about how geography and geographers engage with research on global food and nutrition security, but it certainly exemplifies the strong and distinguishing contribution provided by a geographical perspective.
The crux of this contribution relates to the importance of context and scale. For we three geographers at the LCIRAH conference, listening to those from other disciplines present their research what we felt to be often overlooked were awareness and consideration for how space and place might have influenced the findings, and consideration of how the same research might yield different results in another context. For example, much of the research on global food and nutrition security carried out by economists, nutrition scientists, and public health specialists uses large datasets where the vitality of space and place rarely emerge from the background. Their incorporation into analysis tends to be limited to use as dependent variables in testing for associations of significance. Hence, researchers from these other traditions may find that social, economic, or health outcomes may be significantly associated with place-based indicators (for example, the different states or regions from where data were collected), but without ancillary information about the less tangible spatialities of these places (including the richness of historico-geographical context or the lived experiences of inhabitants). Deeper questions about why these associations may exist tend to be disregarded or not even recognised. Comparably, these research traditions also make only occasional use of spatial methods and indicators, such as the Cartesian measurement of the distance from household to market or town, as proxies or catchall categories for 'space' or 'geography'. But again, if these spatial proxies are found to be significant for a particular social or economic outcome, the question of why these associations exist can often remain unanswered. These observations highlight the potential contribution of geographical perspectives to studies of food and nutrition security. As a general rule, geographers 
tend to narrate their research according to an abiding concern for how social and economic processes unfold in place and space. Explanation is anchored to an understanding of the active roles of place and space in shaping food environments or health outcomes. This narrative practice of contextualising and of listening to voices from below includes an obligation to understand and report issues in terms of the frameworks of those who experience them. Consistent with this philosophy, a strong tradition of geographical research is to investigate those issues with participants, rather than consider people's circumstances abstractly. This tradition is encapsulated in action research methodologies and recently developed approaches in the area of participatory GIScience. Via these means, deeper insights and situated knowledges are created, and these help to answer the 'why' questions prompted by large dataset analyses.

Geographers engage in the production of these types of insights using several sub-disciplinary capabilities. First, geographers are carriers of spatial science expertise. Geographers involved in interdisciplinary research teams can contribute technical and analytical expertise in GIScience, and hence help make better sense of the contextual agro-ecological, meteorological, and anthropic environments that influence food and nutrition security dynamics. This is a rapidly developing field characterised by technological development and the advent of new geospatial datasets, along with new methodologies to interpret and integrate different forms of data derived from differently sourced spatial layers. In the field of food and nutrition security research, analysis can require the integration of agricultural, livelihoods, and dietary data, and increasingly these are spatially geo-referenced. Hence, GIScience has become a more prominent tool in this field.

Second, geographers can contribute to this field of research as area specialists. The tradition of deep research in geography means that many geographers have intimate knowledge of the social, economic, and agro-ecological dynamics of many parts of the world that have key interest in food and nutrition security research. Hence, although some geographers may regard food and nutrition security as an incidental research interest, their deep knowledge of particular places means they are often well-equipped to understand the placebased dynamics relevant to food systems and nutrition outcomes.

Third, geographers' expertise in mixed methods approaches and participant action research can make them adept members of interdisciplinary teams. The field-based orientation of much geographical research means that geographers often possess varied and flexible skillsets. It is not uncommon, for instance, for geographers to build individual research projects around amalgams of quantitative data, GIScience, qualitative interviews, and community-based participant action. At times, this approach contrasts with that by scholars from disciplines where specialisms are rooted tightly to particular analytical approaches or methodologies.

Finally, geographers are often well-positioned to 'join the dots' in food and nutrition security research, and to lubricate interdisciplinary discussions, because strong traditions of analytical and synthetic interdisciplinarity in geography have cultivated open and inductive approaches to research. It is frequently the case that geographers participate in research environments dominated by other disciplinary groupings (agricultural science, economics, and public health and nutrition science among them). For geographers working in these contexts, there is an imperative to speak and write across disciplinary divides. As such, geographers are capable of formulating synthesising insights that may escape the purview of others.

\section{The contribution of this special issue to the study of global food and nutrition security}

This special issue comes at an important juncture in global consideration of food and nutrition security. In 2015, national governments and the international community failed to achieve the Millennium Development Goal (MDG) hunger target, which aimed to halve the proportion of the world's population that was under-nourished over the 25 year period from 1990 to 2015. In the years approaching the MDG deadline, this looming failure, coupled with the global food crises of 2008, prompted heightened policy and research interest in the global persistence of hunger. At the same time, international concern over hunger was augmented by (a) heightened appreciation of the nutritional inadequacies of global diets and a nutrition transition manifesting contradictions of 'hidden hunger' (defined as sufficient calories but insufficient vitamins and minerals in a diet) and (b) a burgeoning global incidence of obesity and nutrition related non-communicable diseases (diabetes, hypertension, cancer). Furthermore, attention to malnutrition in all its forms had occurred against a backdrop of rapidly shifting economic and ecological landscapes relating to food—and 
continues to do so. These shifts have been evident in highly volatile global commodity markets and the environmental stresses of degraded production landscapes, limitations to water and land resources, and the effects of variable climatic conditions in the context of longer-term climate change.

New frameworks and collaborative communities have been constituted to tackle these issues. In recognition of diverse dietary problems wrapped up in these debates, the term 'food security' has progressively been replaced by 'food and nutrition security', recognising that aspirations for an appropriate food system should focus on the quality of diets, measured in terms of human health and people's access to that. Noting the incompatibility between prevailing global food systems and planetary ecosystem limits, a series of Sustainable Development Goals (SDGs) relating to food has been developed as a successor to the MDGs. Whereas the MDGs for hunger had been defined in terms of under-nutrition measured in calories, the SDGs proclaimed food system targets defined in the wider framework of human and ecosystem health, accessibility, affordability, and justice.

Those developing these agendas constructed food and nutrition security research as an increasingly cross-disciplinary undertaking. The LCIRAH conference, mentioned earlier, was explicitly constituted as a forum in which agricultural, nutrition, and social scientists would come together. Such arenas were rare until recently; now university managers and research funders across the world are making greater efforts to encourage the formation of interdisciplinary 'food and nutrition security' clusters that tap into the zeitgeist for collaborative efforts in research and policy-formulation.

Papers in this special issue take readers to places where food and nutrition security is not common. More than 800 million people in the world are under-nourished (FAO, IFAD \& WFP, 2015) and an even larger number have diets with insufficient vitamins and minerals to sustain long-term health, even though they consume sufficient calories to survive. In the pages that follow, the spread of papers approximately reflects the territorial distribution of major sites of food and nutrition insecurity across the globe: four papers report research from sub-Saharan Africa, three from South Asia, and two from Southeast Asia. The sites of research reported here encompass some of the world's most materially deprived human environments. This deprivation is reflected in Binns' and Bateman's research from Sierra Leone, a nation ranked $181^{\text {st }}$ of 187 national jurisdictions in the United Nations Development Program's (UNDP's) Human Development Index (HDI). Omondi's and colleagues' paper refers to Kenya (ranked $145^{\text {th }}$ ); Molitor's and colleagues' paper to Bangladesh (ranked 142 $\left.{ }^{\text {nd }}\right)$; Ayerakwa's paper to Ghana (ranked $140^{\text {th }}$ ); and Myat Thu's and Judge's paper to Timor-Leste (ranked $133^{\text {rd }}$ ) (all data, United Nations Development Program, 2016). McCordic's and Frayne's cross-country study of Southern Africa includes data from Mozambique (ranked $180^{\text {th }}$ ), Malawi (ranked $173^{\text {rd }}$ ), Zimbabwe (ranked $155^{\text {th }}$ ), and Zambia (ranked $\left.139^{\text {th }}\right)$. Two contributions use data from India (the papers by Pritchard et al. and by Choithani), which-despite being an emerging economic power-has the dubious distinction of having more malnourished people than any other country in the world, and a pattern of economic growth that has generated widening inequality (Venneman \& Dubey, 2013). Comparably, Neilson's and Wright's paper on Indonesia focuses on a country that, through sustained economic growth, has emerged as a lower-middle income nation, but continues to be plagued by poverty. In 2015, 7.6 per cent of Indonesia's population was under-nourished, representing a headcount of 19.4 million people (FAO, IFAD \& WFP, 2015, p.46).

Notwithstanding the diversity of research sites and methodological approaches referred to in this special issue, commonalities in a geographical approach to food and nutrition security are apparent. Central among these points of convergence is an emphasis on situating debates on food and nutrition security in their wider contexts. Specifically, the authors tend to position food and nutrition security in terms of historico-geographical contexts, showing how shock events have shaped contemporary intersections of human and biophysical landscapes; or demonstrating how wider socioeconomic dynamics and geopolitical structures influence rapidly changing livelihood environments for the urban and rural poor.

Examples of the former tendency are found in Myat Thu's and Judge's study in Timor-Leste, and Binns' and Bateman's paper on Sierra Leone - two countries wracked by political violence in the recent past. The approaches taken in these two studies are very different. Binns and Bateman use ethnographic methods to compare lived experiences of food and nutrition security between the 1970s and 2014. In contrast to this longitudinal perspective and against the trauma 
of Timor-Leste's recent history, Myat Thu and Judge consider the results from a survey on nutrition and livelihoods they administered there. Similarly, McCordic and Frayne examine how different contexts across cities in Southern Africa led to varied outcomes for the urban poor during the tumult of the global food crisis of 2008. They argue that household income is not the only predictor of household vulnerability to food price shocks, a result that points to the need for multi-dimensional framings. The paper by Neilson and Wright situates contemporary national policy discourse in Indonesia about food and nutrition security in a sensitised reading of recent history. Neilson and Wright contend that the mobilisation of 'food sovereignty' discourses in Indonesia helps explain certain political imperatives for state control of the food supply (especially for staples such as rice) in response to the shocks of the 1998 political transformation of the country and the 2008 global food price crisis. This work represents an articulation of the food sovereignty concept that contrasts with its use in much contemporary social science, where it is employed to emphasise communitybased control of food systems.

Other papers in this special issue have a preeminent concern to situate food and nutrition security in relation to livelihoods more generally. Both Ayerakwa's paper on Ghana and Omondi et al.'s work on Kenya seek to identify what role these production systems play in the food security of urban households, and hence both position urban agriculture within broader food system frames. As both works show, this is a key point of distinction between their studies and earlier literature on urban agriculture, which tended to describe or explain these activities in isolation from wider urban food systems and livelihood dynamics.

The three papers reporting research from South Asia also have strong foci on the relationship between food and nutrition security and people's livelihoods. Pritchard et al. use a case study of two north Indian villages to emphasise the importance of non-agricultural livelihoods in emerging village livelihood environments of rural India. Choithani, in parallel terms, addresses the importance of migration and remittances for food and nutrition security outcomes in rural Bihar. Molitor et al. use evidence from focus group discussions in rural Bangladesh to investigate how decision-making processes by smallholders reflect their mutual status as both producers and consumers of food. Authors of all three papers take pains to emphasise the need to think anew about how rural populations are to be conceptualised given the important roles of non-farm and non-local livelihood activities for household members.

In the final analysis, then, this special issue highlights geographical perspectives and contributions to important global food and nutrition security concerns. The contents serve to exemplify how geographic training, theories, and methods can add value to our understanding of the contextualised histories, geographies, and interdependent structures that interact to form a complex causal soup feeding food and nutrition insecurity. Geographic perspectives enable us to reveal and be sensitive to the lived experiences of people who are food and nutritionally insecure. As such, geographers are well-placed to contribute to effective and ameliorative approaches to this pressing international concern.

\section{Bill Pritchard, ${ }^{1,2}$ (D) Heather Mackay ${ }^{3}$ (D) and Christopher Turner ${ }^{4,5}$ (D)}

${ }^{1}$ School of Geosciences, The University of Sydney, Sydney, New South Wales, Australia, ${ }^{2}$ Institute of Geography, University of Cologne, Köln, Germany, ${ }^{3}$ Department of Geography and Economic History, Umeå University, Umeå, Sweden, ${ }^{4}$ Department of Population Health, London School of Hygiene and Tropical Medicine, London, UK, ${ }^{5}$ Leverhulme Centre for Integrative Research on Agriculture and Health,

London, UK

\section{References}

FAO, IFAD and WFP, 2015. The State of Food Insecurity in the World 2015. Meeting the 2015 International Hunger Targets: Taking Stock of Uneven Progress. Rome: FAO.

United Nations Development Program, 2016. International Human Development Indicators. Available at: http://hdr. undp.org/en/countries. [Accessed 21/09/2016].

Venneman, R. and Dubey, A., 2013. Horizontal and vertical inequalities in India. In: J.C. Gornick and M. Jantti, eds. Income Inequality: Economic Disparities and the Middle Class in Affluent Countries. Palo Alto: Stanford University Press. 